\title{
Prognostic Impact of Splenectomy in Patients with Esophagogastric Junction Carcinoma
}

\author{
MINORU FUKUCHI ${ }^{1,2}$, ERITO MOCHIKI ${ }^{1}$, TORU ISHIGURO ${ }^{1}$, KANA SAITO $^{2}$, HIROSHI NAITOH ${ }^{2}$, \\ YOUICHI KUMAGAI ${ }^{1}$, KEIICHIRO ISHIBASHI $^{1}$ and HIDEYUKI ISHIDA ${ }^{1}$ \\ ${ }^{1}$ Department of Digestive Tract and General Surgery, \\ Saitama Medical Center, Saitama Medical University, Saitama, Japan; \\ ${ }^{2}$ Department of Surgery, Japan Community Health Care Organization, \\ Gunma Chuo Hospital, Gunma, Japan
}

\begin{abstract}
Background/Aim: We evaluated the survival benefit of splenectomy in patients with esophagogastric junction (ECJ) carcinoma. Patients and Methods: We retrospectively examined clinicopathological and survival data for 60 surgically-treated patients with ECJ carcinoma. Results: The 5-year overall survival (OS) rate was 47\%. Splenectomy was performed in 20 patients (30\%). Multivariate Cox regression analysis revealed splenectomy (odds ratio (OR), 2.70; $95 \%$ confidence interval $(C I)=1.06-7.17 ; p=0.04)$ and venous invasion $(O R=3.03 ; 95 \% C I=1.20-9.27 ; p=0.02)$ as significant independent predictors of poorer OS. Splenic hilar lymph node metastasis was not observed. Multivariate logistic regression analysis identified perioperative blood transfusion (BTF) as a significant independent factor associated with splenectomy. Conclusion: The survival benefit of splenectomy in ECJ carcinoma patients may decrease with increasing frequency of perioperative BTF for blood loss. We recommend that splenectomy should be performed carefully when indicated by the extent or invasion of EGJ carcinoma.
\end{abstract}

The incidence of adenocarcinoma of the oesophagogastric junction (EGJ) is increasing in both Western and Eastern countries (1). The Siewert classification of EGJ adenocarcinomas has been widely accepted (2), while the current classification system in Japan designates a tumor as an EGJ carcinoma, regardless of its histological type, when its

This article is freely accessible online.

Correspondence to: Dr. Minoru Fukuchi, Department of Digestive Tract and General Surgery, Saitama Medical Center, Saitama Medical University, 1981, Kamoda, Kawagoe, Saitama 350-8550, Japan. Tel: +81 492283619, Fax: +81 492228865, e-mail: mfukuchi@saitama-med.ac.jp

Key Words: Esophagogastric junction carcinoma, splenectomy, venous invasion, blood transfusion. epicentre is located within $2 \mathrm{~cm}$ proximal or distal to the EGJ (3). Moreover, though in these EGJ carcinomas are less than 4 $\mathrm{cm}$ in diameter, the algorithm was established to provide a tentative standard for lymphadenectomy based on the results of a retrospective multi-institutional study in Japanese guidelines (4). However, the final results of this study did not alter the recommendations, and the optimal surgical procedures for EGJ carcinoma, including the surgical approach (transthoracic or transhiatal), range of lymphadenopathy and type of gastrectomy remain controversial.

The European Society for Medical Oncology clinical practice guidelines recommend D2 gastrectomy for curable gastric cancer. However, splenectomy is not recommended unless the tumor is directly infiltrating the spleen $(5,6)$. In contrast, Japanese guidelines include splenectomy in D2 total gastrectomy (3). A recent randomised trial reported that splenectomy should be avoided because it increased operative morbidity without improving survival in patients undergoing total gastrectomy for proximal gastric cancer not invading the greater curvature (7). Moreover, a previous study reported that splenic hilar lymph node dissection could be omitted from EGJ carcinoma surgery without decreasing curability, based on the index of estimated benefit from lymph node dissection (8). However, this study did not establish the value of splenectomy or not in patients with EGJ carcinoma.

Further information regarding the survival benefits of splenectomy will help determine the optimal surgical procedure in patients with ECJ carcinoma. We retrospectively examined clinicopathological and survival data for surgically treated patients with ECJ carcinoma, to determine the benefits of splenectomy.

\section{Patients and Methods}

Patients. We retrospectively reviewed a database of 60 patients with EGJ carcinoma who had undergone macroscopically complete resection (R0 or R1) at Saitama Medical Center, Saitama Medical University, or Gunma Chuo Hospital between July 2005 and 
August 2017. The selection criteria for the type of surgical procedure and techniques were the same at the two institutions, and splenectomy was performed purely for oncological reasons. We excluded 10 patients with stage IA ECJ carcinoma who were treated without splenectomy, but who remained alive with no recurrence. This retrospective study was approved by the local ethics committee of Saitama Medical Centre of Saitama Medical University (No. 613- III).

ECJ carcinoma was defined as a tumor with a center located within $2 \mathrm{~cm}$ proximal or distal to the EGJ, according to the Japanese Gastric Cancer Association (JGCA) classification (9). T tumor staging was performed according to the Union for International Cancer Control pTNM staging guidelines, 7th edition (10). Surgical complications were assessed by the Clavien-Dindo classification (11). Terminology defined by the JGCA classification was used to avoid unnecessary confusion (9).

Statistical analysis. Continuous variables are expressed as medians and ranges. Categorical and continuous variables were grouped according to standard thresholds. Univariate and multivariate survival analyses were carried out using the Cox proportional hazard regression model. Significant factors associated with splenectomy were investigated using univariate and multivariate logistic regression analyses. Factors with a $p$-value $<0.05$ according to univariate analysis were assessed by multivariate analysis. Odds ratios (ORs) with 95\% confidence intervals (CIs) were calculated for the univariate and multivariate analyses. Survival curves were drawn by the Kaplan-Meier method and compared with the logrank test. All statistical analyses were performed using JMP 5.0 software (SAS Institute, Cary, NC, USA).

\section{Results}

Patient characteristics. The characteristics of 60 patients with ECJ carcinoma are presented in Table I. There were 51 male and 9 female patients with a median age of 70 years. The tumors were located in the GE region in 45 patients, and the median tumor size was $60 \mathrm{~mm}$. The thoracoabdominal and transhiatal approaches were used in 31 and 29 patients, respectively. Splenectomy was performed in 20 patients (30\%). The median numbers of dissected and involved nodes were 36 and three, respectively. The median intraoperative blood loss (IBL) was $530 \mathrm{ml}$, and perioperative blood transfusion (BTF) was performed in 15 patients $(25 \%)$. Grade II or higher complications occurred in 18 patients. Fifty-three patients underwent R0 resection and seven underwent R1 resection. Thirty-four patients received adjuvant chemotherapy, predominantly with S-1 agents.

Survival. The 5-year overall survival (OS) rate of all patients was $47 \%$, with a median follow-up time of 31 months (range=2-116 months). We selected the following 22 variables for univariate analysis with regard to OS: age $(<70$ $v s . \geq 70$ years), gender (male $v s$. female), location (EG $v s$. $\mathrm{E}=\mathrm{G} / \mathrm{GE})$, tumor size $(<60 v s . \geq 60 \mathrm{~mm})$, histological type (differentiated $v s$. undifferentiated), tumor depth (T1b, 2 or 3 vs. T4a or 4b), nodal stage (N0, 1 or 2 vs. N3), TNM stage
Table I. Clinicopathological characteristics of 60 patients with esophagogastric junction carcinoma.

\begin{tabular}{|c|c|}
\hline \multicolumn{2}{|l|}{ Characteristics } \\
\hline Median age (range), years & $70(33-75)$ \\
\hline \multicolumn{2}{|l|}{ Gender, $\mathrm{n}$} \\
\hline Male/female & $51 / 9$ \\
\hline \multicolumn{2}{|l|}{ Location, $\mathrm{n}$} \\
\hline $\mathrm{EG} / \mathrm{E}=\mathrm{G} / \mathrm{GE}$ & $12 / 3 / 45$ \\
\hline Median tumor size (range), $\mathrm{mm}$ & $60(15-105)$ \\
\hline \multicolumn{2}{|l|}{ Histological type, $\mathrm{n}$} \\
\hline Differentiated/undifferentiated & $33 / 27$ \\
\hline \multicolumn{2}{|l|}{ Tumor depth, $\mathrm{n}$} \\
\hline $\mathrm{T} 1 \mathrm{~b} / 2 / 34 \mathrm{a} / 4 \mathrm{~b}$ & $1 / 7 / 32 / 17 / 3$ \\
\hline \multicolumn{2}{|l|}{ Nodal stage, $\mathrm{n}$} \\
\hline $\mathrm{N} 0 / 1 / 2 / 3$ & $18 / 10 / 16 / 16$ \\
\hline \multicolumn{2}{|l|}{ TNM stage, $\mathrm{n}$} \\
\hline IB/II/III/IV & $5 / 15 / 33 / 7$ \\
\hline Median esophageal invasion (range), $\mathrm{mm}$ & $20(2-54)$ \\
\hline Median gastric invasion (range), $\mathrm{mm}$ & $34(10-90)$ \\
\hline \multicolumn{2}{|l|}{ Lymphatic invasion, $\mathrm{n}$} \\
\hline $1 \mathrm{y} 0 / 1 / 2 / 3$ & $15 / 17 / 18 / 10$ \\
\hline \multicolumn{2}{|l|}{ Venous invasion, $\mathrm{n}$} \\
\hline $\mathrm{v} 0 / 1 / 2 / 3$ & $10 / 13 / 29 / 8$ \\
\hline \multicolumn{2}{|l|}{ Approach, $\mathrm{n}$} \\
\hline Thoracoabdominal/transhiatal & $31 / 29$ \\
\hline \multicolumn{2}{|l|}{ Type of gastrectomy, $\mathrm{n}$} \\
\hline Total/proximal & $42 / 18$ \\
\hline \multicolumn{2}{|l|}{ Splenectomy, $\mathrm{n}$} \\
\hline No/yes & $40 / 20$ \\
\hline \multicolumn{2}{|l|}{ Lymphadenectomy, $\mathrm{n}$} \\
\hline $\mathrm{D} 1 / 2$ & $28 / 32$ \\
\hline Median dissected nodes (range), $\mathrm{n}$ & $36(9-96)$ \\
\hline Median involved nodes (range), $\mathrm{n}$ & $36(9-96)$ \\
\hline Median operating time (range), min & $275(139-580)$ \\
\hline Median perioperative blood loss (range), $\mathrm{ml}$ & $530(50-3100)$ \\
\hline \multicolumn{2}{|l|}{ Intraoperative transfusion, $\mathrm{n}$} \\
\hline No/yes & $45 / 15$ \\
\hline \multicolumn{2}{|l|}{ Complications*, n } \\
\hline Grade I/II/III/IV & $8 / 10 / 7 / 1$ \\
\hline \multicolumn{2}{|l|}{ Residual tumor, $\mathrm{n}$} \\
\hline $\mathrm{R} 0 / 1$ & $53 / 7$ \\
\hline \multicolumn{2}{|l|}{ Neoadjuvant chemotherapy, $\mathrm{n}$} \\
\hline No/Yes & $57 / 3$ \\
\hline \multicolumn{2}{|l|}{ Adjuvant chemotherapy, $\mathrm{n}$} \\
\hline $\mathrm{No} / \mathrm{Yes}$ & $26 / 34$ \\
\hline
\end{tabular}

*Based on the Clavien-Dindo classification.

(IB or II $v s$. III or IV), esophageal invasion $(<20 v s . \geq 20$ $\mathrm{mm}$ ), gastric invasion ( $<34 v s . \geq 34 \mathrm{~mm}$ ), type of approach (thoracoabdominal vs. transhiatal), type of gastrectomy (total $v s$. proximal), splenectomy (yes vs. no), lymphadenectomy (D1 vs. D2), lymphatic invasion (ly0 or $1 \mathrm{vs}$. ly2 or 3), venous invasion (v0 or 1 vs. v2 or 3 ), operating time $(<275$ $v s . \geq 275 \mathrm{~min}), \mathrm{IBL}(<530 v s . \geq 530 \mathrm{ml})$, perioperative BTF (yes $v s$. no), toxicity grade (grade 0 or I vs. grade II, III or 
Table II. Univariate and multivariate Cox regression analyses for overall survival.

\begin{tabular}{|c|c|c|c|c|c|}
\hline \multirow[t]{2}{*}{ Variables } & \multirow[b]{2}{*}{$\mathrm{N}$} & \multicolumn{2}{|c|}{ Univariate } & \multicolumn{2}{|c|}{ Multivariate } \\
\hline & & Odds ratio $(95 \% \mathrm{CI})$ & $p$-Value & Odds ratio $(95 \% \mathrm{CI})$ & $p$-Value \\
\hline \multicolumn{6}{|c|}{ Nodal stage } \\
\hline No, 1,2 & 44 & 1 & & 1 & \\
\hline N3 & 16 & $3.62(1.56-7.98)$ & $<0.01$ & $2.27(0.79-7.00)$ & 0.13 \\
\hline \multicolumn{6}{|l|}{ TNM stage } \\
\hline IB, II & 20 & 1 & & 1 & \\
\hline III, IV & 40 & $2.51(1.02-7.52)$ & 0.04 & $1.25(0.31-5.15)$ & 0.76 \\
\hline \multicolumn{6}{|c|}{ Lymphatic invasion } \\
\hline ly0 0,1 & 32 & 1 & & $0.57(0.16-1.91)$ & 0.36 \\
\hline ly 2,3 & 28 & $2.83(1.09-5.47)$ & 0.03 & 1 & \\
\hline \multicolumn{6}{|c|}{ Venous invasion } \\
\hline $\mathrm{v} 0,1$ & 23 & 1 & & 1 & \\
\hline v2, 3 & 37 & $3.19(1.30-9.55)$ & 0.01 & $3.03(1.20-9.27)$ & 0.02 \\
\hline \multicolumn{6}{|c|}{ Splenectomy } \\
\hline No & 40 & 1 & & 1 & \\
\hline Yes & 20 & $3.03(1.40-6.79)$ & 0.01 & $2.70(1.06-7.17)$ & 0.04 \\
\hline \multicolumn{6}{|c|}{ Adjuvant chemotherapy } \\
\hline No & 26 & 1 & & 1 & \\
\hline Yes & 34 & $2.54(1.14-6.22)$ & 0.02 & $1.83(0.56-6.62)$ & 0.32 \\
\hline
\end{tabular}

CI: Confidence interval.

Table III. Univariate and multivariate logistic regression analyses for splenectomy.

\begin{tabular}{|c|c|c|c|c|c|}
\hline \multirow[t]{2}{*}{ Variables } & \multirow[b]{2}{*}{$\mathrm{N}$} & \multicolumn{2}{|c|}{ Univariate } & \multicolumn{2}{|c|}{ Multivariate } \\
\hline & & Odds ratio $(95 \% \mathrm{CI})$ & $p$-Value & Odds ratio $(95 \% \mathrm{CI})$ & $p$-Value \\
\hline \multicolumn{6}{|c|}{ Gastric invasion; $\mathrm{mm}$} \\
\hline$<34$ & 30 & 1 & & 1 & \\
\hline$\geq 34$ & 30 & $3.50(1.15-11.7)$ & 0.03 & $2.94(0.67-14.5)$ & 0.16 \\
\hline \multicolumn{6}{|c|}{ TNM stage } \\
\hline IB, II & 20 & 1 & & 1 & \\
\hline III, IV & 40 & $4.19(1.17-20.0)$ & 0.04 & $4.72(0.85-36.6)$ & 0.10 \\
\hline \multicolumn{6}{|c|}{ Lymphadenectomy } \\
\hline D1 & 28 & 1 & & 1 & \\
\hline D2 & 32 & $4.06(1.30-14.5)$ & 0.02 & $4.40(1.03-23.1)$ & 0.06 \\
\hline \multicolumn{6}{|c|}{ Residual tumor } \\
\hline R0 & 53 & 1 & & 1 & \\
\hline R1 & 7 & $6.33(1.22-47.7)$ & 0.04 & $2.74(0.34-28.7)$ & 0.36 \\
\hline \multicolumn{6}{|c|}{ Intraoperative blood loss; ml } \\
\hline$<530$ & 29 & 1 & & 1 & \\
\hline$\geq 530$ & 31 & $4.50(1.43-16.2)$ & 0.01 & $3.71(0.79-19.9)$ & 0.10 \\
\hline \multicolumn{6}{|c|}{ Perioperative blood transfusion } \\
\hline No & 45 & 1 & & 1 & \\
\hline Yes & 15 & $7.00(2.02-27.3)$ & $<0.01$ & $5.45(1.15-30.7)$ & 0.04 \\
\hline
\end{tabular}

CI: Confidence interval.

IV), residual tumor (R0 vs. R1) and adjuvant chemotherapy (yes vs. no). According to univariate analysis, nodal stage $(p<0.01)$, TNM stage $(p=0.04)$, lymphatic invasion $(p=0.01)$, venous invasion $(p=0.01)$, splenectomy $(p=0.01)$ and adjuvant chemotherapy $(p=0.02)$ were significantly associated with poorer OS. Multivariate Cox regression analysis identified venous invasion (OR, 3.03; 95\% CI, 1.209.27; $p=0.02$ ) and splenectomy (OR, 2.70; 95\%CI, 1.06- 
7.17; $p=0.04)$ as significant independent predictors of poorer OS (Table II). The 40 patients treated with spleen preservation exhibited a 5-year OS rate of 63\%, and the 20 patients treated with splenectomy exhibited a 5-year OS rate of $25 \%$. Patients treated with spleen preservation had a significantly longer OS than those treated with splenectomy $(p<0.01)$ (Figure 1).

Factors associated with splenectomy. We examined the factors significantly associated with the performance of splenectomy for EGJ carcinoma by logistic regression analysis. Univariate analysis revealed gastric invasion, TNM stage, lymphade-nectomy, residual tumor, IBL and perioperative BTF as significantly associated with splenectomy, while perioperative BTF was the only significant independent factor associated with splenectomy according to multivariate analysis (Table III). No incidental splenic hilar lymph node metastasis was observed in the present study (data not shown).

\section{Discussion}

The results of this study identified splenectomy and venous invasion as independent factors associated with poorer OS in patients with ECJ carcinoma undergoing macroscopically complete resection. Our data also indicated that splenectomy for EGJ carcinoma was significantly associated with an increasing frequency of perioperative BTF.

In terms of the impact of splenectomy on surgical outcome, a recent randomised trial reported that it failed to improve survival in patients with proximal gastric cancer not invading the greater curvature (7). Moreover, another study reported that splenectomy with splenic hilar lymph node dissection had no survival benefit in patients with EGJ carcinoma (8). In the current study, patients treated with spleen preservation had a significantly longer OS than those treated with splenectomy. Moreover, splenectomy itself was an independent unfavourable factor in patients with ECJ carcinoma, and no splenic hilar lymph node metastasis was observed. It may, thus, be important for splenectomy to be performed carefully when indicated by the extent or invasion of EGJ carcinoma.

The present analysis identified venous invasion as an unfavourable prognostic factor in patients with EGJ carcinoma. Several previous studies have identified a number of prognostic factors for gastric cancer, with lymph node metastasis being the strongest prognostic factor after curative resection (5), and venous invasion only reported as an unfavourable prognostic factor in patients with IB stage gastric cancer without lymph node metastasis (12). ECJ carcinoma patients with venous invasion may thus have a poor prognosis compared with gastric cancer, and may benefit from the effective use of adjuvant chemotherapy.

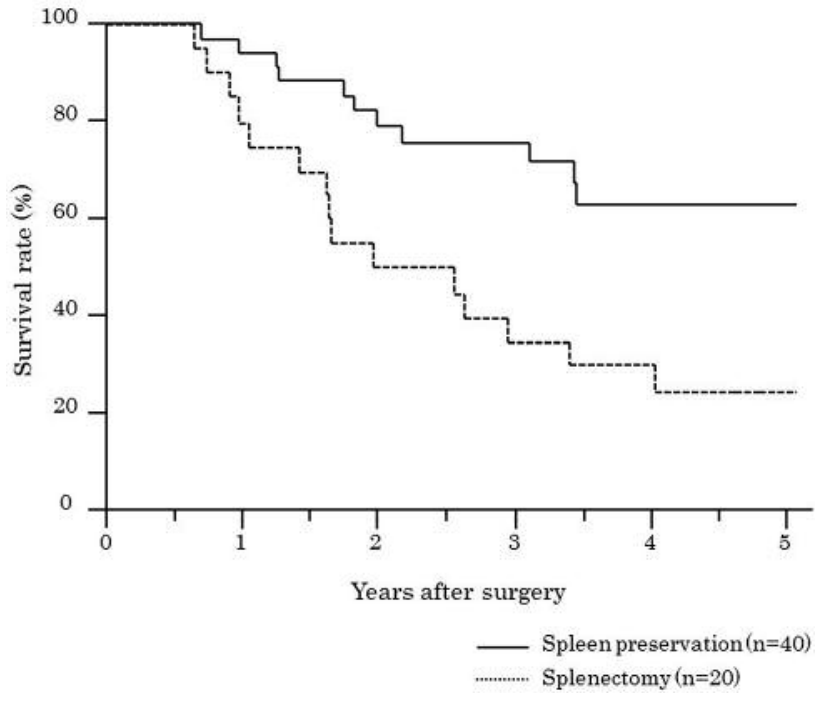

Figure 1. Cumulative overall survival (OS) of 60 patients with esophagogastric junction carcinoma treated with or without splenectomy. The cumulative OS of 40 patients treated with spleen preservation was significantly better than that of 20 patients treated with splenectomy $(p<0.01)$.

In another study, splenectomy was significantly associated with a higher rate of infectious complications in patients with gastric or EGJ carcinoma (13). In the present study, perioperative BTF was a significant factor associated with splenectomy in patients with EGJ carcinoma. BTF is required when performing complex surgery with a large IBL; however, BTF may adversely cause dysfunction of the immune system and malignant transformation of neoplastic cells $(14,15)$. Several studies have attempted to evaluate the influence of perioperative BTF on the prognosis of gastric cancer patients, but the results have varied. Ojima et al. (16) and Kanda et al. (17) explored prognostic factors in patients with stage I-IV and II/III gastric cancer, respectively, and identified perioperative BTF as an independent unfavourable factor. In contrast, Zhou et al. (18) found that perioperative BTF was not an independent prognostic factor in patients with stage I-III gastric cancer, and Pacelli et al. (19) reported no significant difference in survival of stage I-IV gastric cancer patients in relation to the receipt of BTF, regardless of splenectomy. Based on these previous findings, the prognostic effect of BTF in gastric cancer patients remains unclear. The surgical procedure for EGJ carcinoma may be more complex than that for gastric cancer, because of its approach or the extent of lymphadenectomy, and BTF for excessive IBL may thus be more common during surgery for EJG carcinoma compared with gastric cancer (20). However, our current results suggest that BTF for excessive IBL associated with complex surgery, in addition to splenectomy, may lead to poor outcomes in patients with ECJ carcinoma. 


\section{Conclusion}

In conclusion, the survival benefits of splenectomy in patients with ECJ carcinoma may decrease in line with the increasing frequency of perioperative BTF for blood loss. Splenectomy should thus be performed carefully when indicated by the extent or invasion of the EGJ carcinoma. Although the current retrospective study was performed in a small patient population and was therefore subject to selection bias, the findings warrant further prospective studies with larger sample sizes to determine the optimal surgical treatment strategy in patients with ECJ carcinoma.

\section{Conflicts of Interest}

Minoru Fukuchi and the other co-authors have no conflict of interest.

\section{References}

1 Oda I, Abe S, Kusano C, Suzuki H, Nonaka S, Yoshinaga S, Taniguchi H, Shimoda T and Gotoda T: Correlation between endoscopic macroscopic type and invasion depth for early esophagogastric junction adenocarcinomas. Gastric Cancer 14: 22-27, 2011

2 Siewert JR and Stein HJ: Classification of adenocarcinoma of the oesophagogastric junction. Br J Surg 85: 1457-1459, 1998.

3 Japanese Gastric Cancer Association: Japanese gastric cancer treatment guidelines 2014 (ver. 4). Gastric Cancer 20: 1-19, 2017.

4 Yamashita H, Seto Y, Sano T, Makuuchi H, Ando N and Sasako M; Japanese Gastric Cancer Association and the Japan Esophageal Society: Results of a nation-wide retrospective study of lymphadenectomy for esophagogastric junction carcinoma. Gastric Cancer 20(Suppl 1): 69-83, 2017.

5 Hartgrink HH, Jansen EP, van Grieken NC and van de Velde CJ: Gastric cancer. Lancet 374: 477-490, 2009.

6 Okines A, Verheij M, Allum W, Cunningham D and Cervantes A; ESMO Guidelines Working Group: Gastric cancer: ESMO Clinical Practice Guidelines for diagnosis, treatment and followup. Ann Oncol 21(Suppl 5): v50-54, 2010.

7 Sano T, Sasako M, Mizusawa J, Yamamoto S, Katai H, Yoshikawa $\mathrm{T}$, Nashimoto A, Ito $\mathrm{S}$, Kaji M, Imamura $\mathrm{H}$, Fukushima N and Fujitani K; Stomach Cancer Study Group of the Japan Clinical Oncology Group: Randomized Controlled Trial to Evaluate Splenectomy in Total Gastrectomy for Proximal Gastric Carcinoma. Ann Surg 265: 277-283, 2017.

8 Goto H, Tokunaga M, Sugisawa N, Tanizawa Y, Bando E, Kawamura T, Niihara M, Tsubosa Y and Terashima M: Value of splenectomy in patients with Siewert type II adenocarcinoma of the esophagogastric junction. Gastric Cancer 16: 590-595, 2011.

9 Japanese Gastric Cancer Association. Japanese classification of gastric carcinoma: Third English edition. Gastric Cancer 14: 101-112, 2011.

10 Sobin LH, Gospodarowicz MK and Wittekind CH: TNM Classification of Malignant Tumours. Seven Edition. Oxford: Wiley-Blackwell, 2009.
11 Clavien PA, Barkun J, de Oliveira ML, Vauthey JN, Dindo D, Schulick RD, de Santibañes E, Pekolj J, Slankamenac K, Bassi C, Graf R, Vonlanthen R, Padbury R, Cameron JL and Makuuchi M: The Clavien-Dindo classification of surgical complications: five-year experience. Ann Surg 250: 187-196, 2009.

12 Araki I, Hosoda K, Yamashita K, Katada N, Sakuramoto S, Moriya $\mathrm{H}$, Mieno $\mathrm{H}$, Ema A, Kikuchi S, Mikami $\mathrm{T}$ and Watanabe M: Prognostic impact of venous invasion in stage IB node-negative gastric cancer. Gastric Cancer 18: 297-305, 2015.

13 Weitz J, Jaques DP, Brennan M and Karpeh M: Association of splenectomy with postoperative complications in patients with proximal gastric and gastroesophageal junction cancer. Ann Surg Oncol 11: 682-689, 2004.

14 Blumberg $\mathrm{N}$ and Heal JM: Transfusion-induced immunomodulation and its possible role in cancer recurrence and perioperative bacterial infection. Yale J Biol Med 63: 429-433, 1990.

15 van Hilten JA, van de Watering LM, van Bockel JH, van de Velde CJ, Kievit J, Brand R, van den Hout WB, Geelkerken RH, Roumen RM, Wesselink RM, Koopman-van Gemert AW, Koning $\mathrm{J}$ and Brand A: Effects of transfusion with red cells filtered to remove leucocytes: randomised controlled trial in patients undergoing major surgery. BMJ 328: 1281, 2004.

16 Ojima T, Iwahashi M, Nakamori M, Nakamura M, Naka T, Katsuda M, Iida T, Hayata K and Yamaue H: Association of allogeneic blood transfusions and long-term survival of patients with gastric cancer after curative gastrectomy. J Gastrointest Surg 13: 1821-1830, 2009.

17 Kanda M, Kobayashi D, Tanaka C, Iwata N, Yamada S, Fujii T, Nakayama G, Sugimoto H, Koike M, Nomoto S, Murotani K, Fujiwara $\mathrm{M}$ and Kodera $\mathrm{Y}$ : Adverse prognostic impact of perioperative allogeneic transfusion on patients with stage II/III gastric cancer. Gastric Cancer 19: 255-263, 2016.

18 Zhou HY, Yi W, Wang J, Zhang J, Wang WJ and Hu ZQ: Association of perioperative allogeneic blood transfusions and prognosis of patients with gastric cancer after curative gastrectomy. Am J Surg 208: 80-87, 2014.

19 Pacelli F, Rosa F, Marrelli D, Pedrazzani C, Bossola M, Zoccali M, Marchet A, Di Cosmo M, Roata C, Graziosi L, Cavazzoni E, Covino M, D'Ugo D, Roviello F, Nitti D and Doglietto GB: Do perioperative blood transfusions influence prognosis of gastric cancer patients? Analysis of 927 patients and interactions with splenectomy. Ann Surg Oncol 18: 1615-1623, 2011.

20 Pultrum BB, van Bastelaar J, Schreurs LM, van Dullemen HM, Groen H, Nijsten MW, van Dam GM and Plukker JT: Impact of splenectomy on surgical outcome in patients with cancer of the distal esophagus and gastro-esophageal junction. Dis Esophagus 21: 334-339, 2008 . 